Collection: IUFRO RG 7.01 (2010) - Antalya (Turkey)

Adaptation of Forest Ecosystems to Air Pollution and Climate Change

Guest Editors: Elena Paoletti, Yusuf Serengil

\section{Soil drench of ethylenediurea (EDU) protects sensitive trees from ozone injury}

\author{
Paoletti E ${ }^{(1)}$, Manning WJ (2), Ferrara AM ${ }^{(3)}$, Tagliaferro F $^{(3)}$
}

Ozone $\left(\mathrm{O}_{3}\right)$ is the air pollutant of major concern for vegetation. Levels in Mediterranean cities may exceed the criteria for vegetation protection. Ozone may induce a number of plant responses, e.g., visible injury on the leaves, that affect the ornamental value of urban forests. Antioxidant application may protect sensitive plants from ozone. The most successful synthetic antioxidant is ethylenediurea (EDU). Here we set the optimal EDU dose and concentration (260 $\mathrm{mg} \mathrm{m}^{-2}$ leaf, $450 \mathrm{ppm}$ ) for protecting adult Fraxinus excelsior trees from ozone visible injury by means of EDU applications as soil drench.

Keywords: Ethylenediurea, EDU, Tropospheric ozone, Urban forests, Ornamental trees

\section{Introduction}

Ozone $\left(\mathrm{O}_{3}\right)$ is the air pollutant of major concern for vegetation, because of its elevated phytotoxicity and widespread distribution (Paoletti 2007). Ozone concentrations in the cities are usually lower than in suburban and rural areas, but levels in Mediterranean cities may exceed the criteria for vegetation protection (Paoletti 2009). Ozone may induce a number of plant responses - including leaf visible injury, premature leaf senescence, growth reduction, altered water balance, predisposition to other urban stressors like water deficit or pathogen attack - that af fect the ornamental value of urban forests Visible injury usually occurs on leaves as interveinal dark stipples on the upper blade only.

Antioxidant application may protect sensitive plants from ozone injury (Paoletti et al. 2009b). The most successful synthetic antioxidant is $\mathrm{N}$-[2-(2-oxo-1-imidazolidinyl) ethyl]-N'-phenylurea (ethylenediurea, abbre-

(1) IPP-CNR, Via Madonna del Piano 10, I50019 Sesto Fiorentino (FI - Italy); (2) Dept. Plant, Soil and Insect Sciences, University of Massachusetts, Amherst, MA (USA); (3) IPLA, Corso Casale 476, I-10132 Turin (Italy).

@) Elena Paoletti (e.paoletti@ipp.cnr.it)

Received: Apr 06, 2010 - Accepted: Dec 21, 2011

Citation: Paoletti E, Manning WJ, Ferrara AM, Tagliaferro F, 2011. Soil drench of ethylenediurea (EDU) protects sensitive trees from ozone injury. iForest 4: 66-68 [online: 2011-04-06] URL: http://www.sisef. it/iforest $/$ show.php?id=569 viated EDU). EDU is effective in protecting crop and tree species when regularly applied. EDU is rapidly transported in the acropetal direction, probably via the xylem stream, and accumulates in the apoplastic space of the leaves, but for a limited time. EDU in leaves is not transported from them to leaves that have developed since EDU treatment, hence the need for application at 1-3 week intervals to provide continuous protection.

Small-size plants may be treated by foliar spray including a surfactant drop as wetting agent. Based on past observations of foliar ozone-like injury, one hibiscus hedge (Hibiscus syriacus cv. Minerva), with plants known to be ozone-sensitive, was selected on the hills around Turin ("Millerose" Park, Italy) and treated weekly by spraying 300 ppm EDU over one growing season. EDU significantly reduced ozone visible injury $(-75 \%)$, thus confirming the injury was caused by ambient ozone (Paoletti et al. 2009a). Seeds were collected and seedlings were exposed to ozone in filtered (no $\left.\mathrm{O}_{3}\right) v s$. not-filtered $\left(+30 \mathrm{ppb}_{3}\right)$ open-top chambers. Visible injury was similar to that occurring under ambient conditions, thus confirming not only that ozone was the cause of injury, but also that the ozone sensitivity was heritable.

The application of EDU to adult ornamental trees is technically difficult. The most successful techniques for trees have been trunk injection, by means of a low-pressure pump, and trunk infusion, by gravitational pressure. Both trunk injection and infusion require making an entry hole in a tree trunk and provision of a reservoir of the chemical. The former method was applied to young
Poplar cuttings (Ainsworth et al. 1996, Ainsworth \& Ashmore 1992, Bortier et al. 2001). The latter method, where the chemical is taken up by transpiration of the tree, was applied to adult Ash trees in the "Millerose" Park of Turin, Italy (Paoletti et al. 2007a, 2007b, 2008). The size of these Ash trees was the largest in all EDU experiments on tree species, i.e., $13-17 \mathrm{~cm}$ diameter at breast height (16-31 years old). The concentration to provide protection from visible ozone injury was $450 \mathrm{ppm}$ EDU, corresponding to $13-26 \mathrm{mg} \mathrm{m}^{-2}$ leaf, every three weeks. Protection was recoded at all three levels in the crown.

Although EDU was successful in both protecting from ozone visible injury and highlighting some mechanisms of ozone injury, gravitational infusion required at least 12 holes in the trunk, i.e. two holes on the opposite sides of the trunk every 21 days from May to September. Additional holes must be drilled in case of ineffective uptake. Therefore, this technique cannot be recommended for long-term treatments of trees. A preliminary investigation with $6 \mathrm{~L}$ of EDU solution $(450 \mathrm{ppm})$ applied as drench in 12 soil holes (5-cm diameter, $10-\mathrm{cm}$ depth) that were evenly distributed around every tree (50-60 $\mathrm{cm}$ distance from the tree base) was carried out on the same symptomatic Ash trees and induced a non significant decrease in visible injury during the growing season 2007 (Paoletti et al. 2009b). This paper show the result of a new soil drench experiment, with the main aim of standardizing an effective EDU dose for the protection of adult trees from ozone visible injury.

\section{Materials and Methods}

The experimental site was located at the "Millerose" park in Turin (Italy, 45 4' $25^{\prime}$ " N, $7^{\circ} 43^{\prime} 46^{\prime}$ E). Based on past observations (Paoletti et al. 2007a, 2007b, 2008, 2009b), eight young and six adult ash (Fraxinus excelsior L.) trees showing visible ozone injury in previous years were selected and treated with $450 \mathrm{ppm}$ EDU as soil drench every three weeks. Ooze tubes (engineered watering solutions, Atlanta, Georgia, USA) equipped with drip tubing were put around the base of our trees. Half of the trees were treated with water and half with EDU $(100 \%$ active ingredient). They were exposed to ambient ozone levels for the growing season 2008. The EDU dose was $260 \mathrm{mg} \mathrm{m}^{-2}$ leaf, i.e., 3.6 times higher than that applied in 2007 (Paoletti et al. 2009b), when a non significant reduction of symptoms was observed. The total leaf area per tree was estimated on a DBH (Diameter at Breast Height) basis by using the data in Le Goff et al. (2004). Visible injury was assessed in September on two 1-year-old sun shoot per 
Fig. 1 - Percent $( \pm$ SE) of injured leaflets per shoot (LA), injured surface area per injured leaflet (AA) and plant injury index (PII) in young and adult Ash trees, treated with ethylenediurea (EDU) or water (WAT) as soil drench for one growing season.

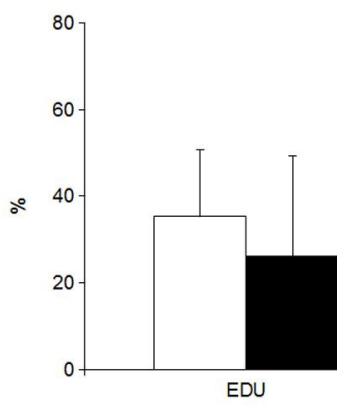

LA
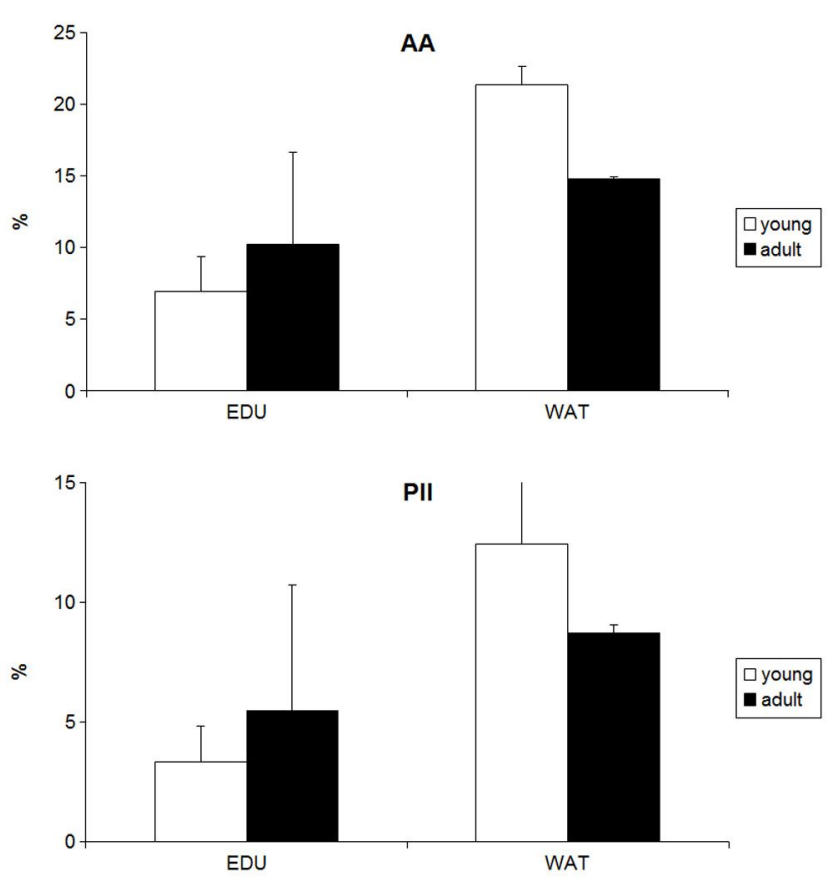

tree, gathered from the lower third of a crown, by counting the number of leaflets showing interveinal stipples and expressed as the percentage of injured leaflets of all leaflets present (LA), and by visually assessing the percent surface injury (according to Innes et al. 2001) and expressed as the percentage of injured leaflet surface per symptomatic leaflet surface (AA). A Plant Injury Index (PII) was then calculated as follows (Paoletti et al. 2009a - eqn. 1):

$$
P I I=\frac{(L A \cdot A A)}{100}
$$

After checking for normal distribution, a two-way analysis of variance (tree age class $x$ treatment) was applied on the data, after arcsin transformation of percents.

Tab. 1 - Levels of significance (p) of a two-way analysis of variance on percent of injured leaflets per shoot (LA), percent of injured surface area per injured leaflet (AA) and a combination of LA and AA [PII $=(\mathrm{LA} \cdot \mathrm{AA}) / 100] .(\mathrm{ns}): \mathrm{p}>0.1 ;(+): \mathrm{p}<0.1 ;(*)$ : $\mathrm{p}<0.05$.

\begin{tabular}{llll}
\hline \multicolumn{1}{c}{ Factor } & \multicolumn{1}{c}{ LA } & \multicolumn{1}{c}{ AA } & \multicolumn{1}{c}{ PII } \\
\hline Tree age class (young $v s$. adult) & $0.810 \mathrm{~ns}$ & $0.753 \mathrm{~ns}$ & $0.871 \mathrm{~ns}$ \\
Treatment (EDU $v s$. water) & $0.138 \mathrm{~ns}$ & $0.021 *$ & $0.058+$ \\
Interaction & $0.759 \mathrm{~ns}$ & $0.515 \mathrm{~ns}$ & $0.821 \mathrm{~ns}$ \\
\hline
\end{tabular}

the severity of injury in injured leaflets were reduced by $55 \%$ and $44 \%$, respectively. This level of protection may considerably increase the ornamental value of a tree in an ozone-polluted environment.

In conclusion, soil drench of $450 \mathrm{ppm}$ EDU over the growing season can be successfully used to reduce the extent of ozone injury on the leaves of ornamental trees, provided an optimal dose is set through preliminary ecotoxicology tests.

\section{References}

Ainsworth N, Ashmore MR (1992). Assessment of ozone effects on beech (Fagus sylvatica) by injection of a protectant chemical. Forest Ecology and Management 51: 129-136. - doi: 10.1016/ 0378-1127(92)90479-S

Ainsworth N, Fumagalli I, Giorcelli A, Mignanego L, Schenone G, Vieto L (1996). Assessment of EDU stem injections as a technique to investigate the response of trees to ambient ozone in field conditions. Agricultural Ecosystems and Environment 59: 33-42. - doi: 10.1016/0167. 8809(96)01043-2

Bortier K, Dekelver G, De Temmerman L, Ceulemans R (2001). Stem injection of Populus nigra with EDU to study ozone effects under field conditions. Environmental Pollution 111: 199-208. doi: 10.1016/S0269-7491(00)00075-0

Innes JL, Skelly JM, Schaub M (2001). Ozone and broadleaved species. A guide to the identification of ozone-induced foliar injury. Paul Haupt Verlag, Bern, pp. 136.

Le Goff N, Granier A, Ottorini JM, Peiffer M (2004). Biomass increment and carbon balance of ash (Fraxinus excelsior) trees in an experimental stand in northeastern France. Annals of Forest Science 61: 577-588. - doi: 10.1051/ forest:2004053

Paoletti E (2007). Ozone impacts on forests. CAB Reviews: Persp. Agri. Vet. Sci. Nutr. Nat. Resources 2 (68): 13. - doi: 10.1079/PAVSNNR20072068

Paoletti E (2009). Ozone and urban trees in Italy. Environmental Pollution 157: 1506-1512. - doi: 10.1016/j.envpol.2008.09.019

Paoletti E, Contran N, Manning WJ (2007a). Ethylenediurea (EDU) affects the growth of ozone-sensitive and tolerant Ash (Fraxinus excelsior) trees under ambient $\mathrm{O}_{3}$ conditions. The Scientific World Journal 7 (S1): 128-133. - doi: 10.1100/tsw.2007.21

Paoletti E, Manning WJ, Spaziani F, Tagliaferro F (2007b). Gravitational infusion of ethylenediurea (EDU) into trunks protected adult European ash trees (Fraxinus excelsior L.) from foliar ozone injury. Environmental Pollution 145: 869-873. doi: 10.1016/j.envpol.2006.05.005

Paoletti E, Contran N, Manning WJ, Castagna A, Ranieri A, Tagliaferro F (2008). Protection of ash (Fraxinus excelsior) trees from ozone injury by ethylenediurea (EDU): roles of biochemical changes and decreased stomatal conductance in enhancement of growth. Environmental Pollution 155: 464-472. - doi: 10.1016/j.envpol.2008.01. 
040

Paoletti E, Contran N, Manning WJ, Ferrara AM (2009a). Use of the antiozonant EDU to protect vegetation under Mediterranean conditions: case studies from Italy. Environmental Pollution 157: 1453-1460. - doi: 10.1016/j.envpol.2008.09.021 Paoletti E, Ferrara AM, Calatayud V, Cerveró J, Giannetti F, Sanz MJ, Manning WJ (2009b). De- ciduous shrubs for ozone bioindication: Hibiscus syriacus as an example. Environmental Pollution 157: 865-870. - doi: 10.1016/j.envpol.2008.11. 009 